ORIGINAL ARTICLE

\title{
Assessing individual employee risk factors for occupational asthma in primary aluminium smelting
}

\author{
C G Barnard, D I McBride, H M Firth, G P Herbison
}

Occup Environ Med 2004;61:604-608. doi: 10.1136/oem.2003.009159

See end of article for authors' affiliations

.....................

Correspondence to: Dr C Barnard, Prime Occupational Health, Lot 1, Rockingham Road, Naval Base, Western Australia 6165, Australia; cbarnard@primehealth. com.au

Accepted 8 October 2003

\begin{abstract}
Aims: To assess the significance of individual risk factors in the development of occupational asthma of aluminium smelting (OAAS).

Methods: A matched case-control study nested in a cohort of 545 workers employed in areas with moderate to high levels of smelting dust and fume. The cohort comprised those who had their first preemployment medical examination between 1 July 1982 and 1 July 1995; follow up was until 31 December 2000. Forty five cases diagnosed with OAAS and four controls per case were matched for the same year of pre-employment and age within \pm 5 years. The pre-employment medical questionnaires were examined, blinded as to case-control status, and information obtained on demographics and details of allergic symptoms, respiratory risk factors, respiratory symptoms, and spirometry. Data from the subsequent medical notes yielded subsequent history of hay fever, family history of asthma, full work history, date of termination or diagnosis, and tobacco smoking history at the end-point.

Results: There was a significant positive association between hay fever diagnosed either at or during employment and OAAS (adjusted OR 3.58, 95\% Cl 1.57 to 8.21 ). A higher forced expiratory ratio (FEV ${ }_{1} / \mathrm{FVC} \%$ ) at employment reduced the risk of developing OAAS (adjusted OR $0.93,95 \% \mathrm{Cl} 0.88$ to 0.99). The risk of OAAS was more than three times higher in individuals with an FER of $70.0-74.9 \%$ than in individuals with an FER $\geqslant 80.0 \%$ (adjusted $\mathrm{OR} 3.46,95 \% \mathrm{Cl} 1.01$ to 11.89 ).

Conclusions: Individuals with hay fever may be more susceptible to occupational asthma when exposed to airborne irritants in aluminium smelting. The pathological basis may be reduced nasal filtration and increased bronchial hyperresponsiveness.
\end{abstract}

O ccupational asthma of aluminium smelting (OAAS), also called "potroom asthma", has been a major health issue in aluminium smelting since it was first described in 1936. ${ }^{1}$ Australasian smelters have implemented comprehensive preventative strategies over the past 25 years. These measures reduced the Australasian incidence from $2-4 \%$ of the exposed workforce in 1982 to $0.5 \%$ in 2000 .

A specific cause of OAAS has not been conclusively identified, however many studies implicate exposure to hydrogen fluoride (HF) and particulate fluoride. ${ }^{2-9}$ Few analytical studies have examined OAAS. Most studies have been cross-sectional, and few individual risk factors have been consistently identified. Bronchial hyperresponsiveness (BHR) has been consistently found to be a strong risk factor for OAAS. ${ }^{410-13}$ There have been positive associations with atopy, familial asthma, and cigarette smoking, although these are either small and/or not statistically significant. ${ }^{6}{ }^{14-17}$

In particular, the association between OAAS and atopy is consistently positive, but non-significant, with a small but possibly important increased risk of $20-100 \%$. Some studies that found associations between OAAS and high eosinophil counts and increased IgE may support such a risk. ${ }^{18}{ }^{19}$ The aim of the present study was to identify individual risk factors, particularly those associated with hay fever, in a cohort of aluminium smelter workers.

\section{METHODS}

\section{Study sample}

The cohort consisted of all who had their pre-employment medical examination between I July 1982 and I July 1995 and commenced their employment in areas with at least weekly exposure to fluoride dust and fume (potrooms, potroom maintenance, pot reconstruction, potroom services, carbon rodding, and rodding maintenance). Follow up was until 31 December 2000.

\section{Selection of cases}

The case criteria used were those defined by the Australian Aluminium Council, which is consistent with American Thoracic Society guidelines..$^{20}$ The criteria were:

- Symptoms of dyspnoea, chest tightness, and/or wheezing, often with cough, which may be brought about by exercise

- A period of initial exposure to fluorides of more than two weeks before symptom onset

- Symptoms temporally related to exposure, but often also nocturnal

- Symptoms improve when the subject is away from work for days or longer.

The symptoms were supported by objective evidence of significant reversible airflow obstruction and/or evidence of BHR on testing.

One respiratory physician diagnosed cases at the smelter between 1982 and 2000. Most cases were detected by regular medical surveillance, however, some cases self-referred. Persons with chronic obstructive disease due to welding or metal fume were excluded.

Abbreviations: BHR, bronchial hyperresponsiveness; FER, forced expiratory ratio; $\mathrm{FEV}_{1}$, forced expiratory volume in 1 second; $\mathrm{FVC}$, forced vital capacity; OAAS, occupational asthma of aluminium smelting; WRAS, work related asthmatic symptoms 


\section{Main messages}

- Aluminium smelter workers with hay fever are at increased risk of developing occupational asthma.

- The risk may be identified by BHR testing at preemployment, during the hay fever season, and/or when workers experience hay fever symptoms.

- Appropriate therapy and/or temporary removal from exposure may modify the risk.

\section{Selection of controls}

Controls, four per case, were matched for age ( \pm 5 years) and same year of commencing employment. Exclusion criteria were any respiratory pathology, significant non-transient respiratory symptoms, being investigated for respiratory pathology, and those employed in an aluminium smelter prior to the original pre-employment.

\section{Data collection}

The pre-employment medical questionnaires, examination, and recorded spirometry were examined for all subjects with blinding as to case or control status. Past or present history of hay fever, family history of asthma, past or present history of bronchitis (history of chronic chestiness with associated phlegm), history of asthma before age 15 years, tobacco smoking history at employment (never, ex, and current), past or present history of dermatitis, symptoms of wheeze, and symptoms of regular cough were recorded. Hay fever was defined as seasonal symptoms of itchy, runny nose (allergic rhinitis) with or without associated eye symptoms. Skin testing was not performed.

Physical examination data included height, weight, and ethnicity. Pre-employment spirometric data recorded were the forced vital capacity (FVC), the forced expiratory volume in 1 second $\left(\mathrm{FEV}_{1}\right)$, and forced expiratory ratio (FER) $\left(100 \times \mathrm{FEV}_{\mathrm{l}} / \mathrm{FVC}\right)$. Percent predicted values for the FVC and $\mathrm{FEV}_{1}$ were calculated using in-house equations for Europeans, and equations calculated by de Hamel and Welford, for Maoris and Samoans. ${ }^{21}$

Follow up data included hay fever and family history of asthma diagnosed or disclosed after the onset of employment, full work history while at the smelter, and tobacco smoking history at termination, diagnosis, or at the end date of the study. It was assumed that no subjects would develop OAAS after leaving the smelter.

\section{Exposure assessment}

Occupational hygiene monitoring provided the mean concentrations of respirable dust, fluorides, and sulphur dioxide in all areas. Exposure was categorised in five levels: potrooms and potroom services, grade 4 (highest risk); pot reconstruction, potroom maintenance, and carbon rodding, grade 3; rodding maintenance, grade 2 ; metal products and bath and alumina plant, grade 1 ; and all other areas on site, grade 0 . A cumulative exposure index for each individual was calculated by adding the products of the exposure grade and the years worked in a specific area.

\section{Statistical analysis}

The data were analysed using STATA version 7. Results of the univariate analyses were presented as mean (SD) and proportions. Conditional logistic regression was used to calculate odds ratios and $95 \%$ confidence intervals. Adjustment for fluoride exposure was performed by using the exposure index as a continuous variable as well as grade of exposure as a five level categorical variable.

\section{Policy implications}

- Aluminium smelter workers with hay fever could be tested for BHR during the pollen season and/or when they experience symptoms of hay fever. Those with increased BHR could temporarily be removed from irritant exposures and/or given anti-inflammatory treatment to reduce their susceptibility. BHR testing can be done serially during this period to assess when airway responsiveness returns to normal.

- Aluminium smelter applicants with atopy and an FER of $<80 \%$ at pre-employment should be screened for BHR. Those individuals with BHR and those with an FER $<75 \%$ should either not be accepted for jobs with fluoride exposure or be very carefully monitored during their employment.

\section{RESULTS}

\section{Demographics}

Table 1 summarises the demographic characteristics. The prevalence of hay fever at employment was higher for cases than controls, but both were lower than the general population in New Zealand (35\%). ${ }^{22}$ The total prevalence for hay fever was higher at $16.9 \%$. Ninety six per cent of individuals reporting a family history of asthma at employment did so in first degree relatives. Tobacco smoking was common at employment, more so in cases than controls (51.1\% versus $43.9 \%)$. This differential was still present at diagnosis. Of the non-Europeans only one person was not a Maori or Samoan.

\section{Employment and exposure information}

The majority of cases, and a lesser majority of controls, were first employed as potroom operators: $91.1 \%$ and $73.9 \%$ respectively. Of all the cases and controls in the cohort, 209 $(92.9 \%)$ started work in the potroom area of the plant (potrooms, potroom services, potroom maintenance, and pot reconstruction). This, and matching for year of employment, ensured similar exposures of cases and controls.

The mean (SD) duration of employment was 10.23 (5.53) years, 6.09 (4.04) years for cases (range 0-16 years), and 11.26 (5.38) years for controls (range $2-19$ years). Forty three $(95.6 \%)$ of the cases were still working in potroom areas at diagnosis. The mean exposure index for cases was 21.21 (SD 14.53, range 3-64) and 17.84 (SD 12.64, range 1.5-63) for controls.

Matched analysis for potential individual risk factors Table 2 summarises the matched analysis for potential individual risk factors for OAAS. The odds ratio (OR) for hay fever at employment was raised, although not significantly, both before and after adjustment for confounders (crude OR 1.65, 95\% CI 0.59 to 4.60; adjusted OR 2.28, 95\% CI 0.76 to 6.89). Examining "all hay fever" (identified at employment and subsequently) showed a statistically significant increased risk, enhanced by adjustment for confounding. The magnitude of this association increased further on adjusting for smoking at termination or diagnosis as against smoking status at employment (adjusted OR 3.79, $95 \%$ CI 1.64 to 8.79 ). A family history of asthma, history of bronchitis, childhood asthma, and wheeze at pre-employment revealed increased, but non-significant ORs. There was no significant association between OAAS and tobacco smoking. The remainder of the potential risk factors showed only weak associations. 
Table 1 Characteristics of the cases and controls in the study

\begin{tabular}{|c|c|c|c|}
\hline Characteristic & Controls $(n=180)$ & Cases $(n=45)$ & Total $(n=225)$ \\
\hline Age (years) & $26.7( \pm 6.1)$ & $26.6( \pm 6.3)$ & $26.7( \pm 6.2)$ \\
\hline Height $(\mathrm{cm})$ & $176.9( \pm 5.9)$ & $175.9( \pm 6.6)$ & $176.7( \pm 6.0)$ \\
\hline Weight (kg) & $78.3( \pm 11.7)$ & $79.7( \pm 10.4)$ & $78.6( \pm 11.2)$ \\
\hline Body mass index & $25.0( \pm 3.23)$ & $25.77( \pm 3.2)$ & $25.16( \pm 3.2)$ \\
\hline \multicolumn{4}{|l|}{ Ethnicity } \\
\hline Caucasian & $166(92.2 \%)$ & $40(88.9 \%)$ & $206(91.6 \%)$ \\
\hline Maori/Samoan & $20(11.1 \%)$ & $6(13.3 \%)$ & $26(11.6 \%)$ \\
\hline Other & $1(0.6 \%)$ & 0 & $1(0.4 \%)$ \\
\hline \multicolumn{4}{|l|}{ Tobacco smoking (at employment) } \\
\hline Never smokers & $79(43.9 \%)$ & $18(40 \%)$ & $97(43.1 \%)$ \\
\hline Ex smokers & $22(12.2 \%)$ & $4(8.9 \%)$ & $26(11.6 \%)$ \\
\hline Current smokers & $79(43.9 \%)$ & $23(51.1 \%)$ & $102(45.3 \%)$ \\
\hline \multicolumn{4}{|l|}{ Tobacco consumption } \\
\hline None & $101(56.1 \%)$ & $22(48.9 \%)$ & $123(54.7 \%)$ \\
\hline Light smokers & $10(5.6 \%)$ & $1(2.2 \%)$ & $11(4.9 \%)$ \\
\hline Moderate smokers & $48(26.7 \%)$ & $17(37.8 \%)$ & $65(28.9 \%)$ \\
\hline Heavy smokers & $21(11.7 \%)$ & $5(11.1 \%)$ & $26(11.6 \%)$ \\
\hline Smoking at termination or diagnosis & $59(32.8 \%)$ & $19(42.3 \%)$ & $78(34.7 \%)$ \\
\hline Hay fever at employment & $15(8.5 \%)$ & $6(13.3 \%)$ & $21(9.5 \%)$ \\
\hline Hay fever (total)* & $24(13.3 \%)$ & $14(31.1 \%)$ & $38(16.9 \%)$ \\
\hline Familial asthma (at employment) & $18(10.0 \%)$ & $6(14.3 \%)$ & $24(10.8 \%)$ \\
\hline Familial asthma (total)* & $40(22.2 \%)$ & $12(26.7 \%)$ & $52(23.1 \%)$ \\
\hline Childhood history of asthma & $2(1.1 \%)$ & $1(2.2 \%)$ & $3(1.3 \%)$ \\
\hline Previous history of bronchitis & $1(0.6 \%)$ & $1(2.2 \%)$ & $2(0.9 \%)$ \\
\hline Previous history of dermatitis & $10(5.6 \%)$ & $3(6.7 \%)$ & $13(5.8 \%)$ \\
\hline Cough at employment & $2(1.1 \%)$ & $0(0 \%)$ & $2(0.9 \%)$ \\
\hline Wheeze at employment & $3(1.7 \%)$ & $0(0 \%)$ & $0(0 \%)$ \\
\hline
\end{tabular}

There was a statistically significant negative association between the FER at pre-employment and OAAS (crude OR $0.93, p=0.005$; adjusted OR 0.93, $p=0.017)$. Thus for each
$1 \%$ lower FER at employment the risk of OAAS increased by $7 \%$. In the stratified analysis, there was a significant positive association with an FER of $75.0-79.9 \%$ (crude OR 2.22,

Table 2 The association between OAAS and potential individual risk factors

\begin{tabular}{|c|c|c|c|}
\hline Variable studied & $\begin{array}{l}\text { Crude odds ratios } \\
(95 \% \mathrm{Cl})\end{array}$ & $\begin{array}{l}\text { Adjusted odds ratios* } \\
(95 \% \mathrm{CI})\end{array}$ & $\begin{array}{l}\text { Alternative adjusted odds ratios } † \\
(95 \% \mathrm{Cl})\end{array}$ \\
\hline Hay fever (at employment) & $1.65(0.59$ to 4.60$)$ & $2.28(0.76$ to 6.89$)$ & $2.66(0.84$ to 8.42$)$ \\
\hline All hay fever & $2.91(1.35$ to 6.26$)$ & $3.58(1.57$ to 8.21$)$ & $3.32(1.37$ to 8.05$)$ \\
\hline \multicolumn{4}{|l|}{ Family history of asthma (at employment) } \\
\hline Family history of asthma & 1.60 (0.58 to 4.42$)$ & $1.63(0.57$ to 4.69$)$ & $2.23(0.71$ to 7.03$)$ \\
\hline First degree family history & $1.73(0.61$ to 4.89$)$ & $1.80(0.61$ to 5.33$)$ & $2.25(0.71$ to 7.10$)$ \\
\hline Numbers of family members & $1.59(0.80$ to 3.13$)$ & $1.60(0.79$ to 3.21$)$ & $1.99(0.91$ to 4.34$)$ \\
\hline \multicolumn{4}{|c|}{ Family history of asthma (at employment and subsequently) } \\
\hline Family history of asthma & 1.29 (0.60 to 2.79$)$ & $1.44(0.64$ to 3.24$)$ & 1.28 (0.55 to 2.97$)$ \\
\hline First degree family history & 1.40 (0.64 to 3.07$)$ & $1.60(0.69$ to 3.68$)$ & $1.37(0.58$ to 3.25$)$ \\
\hline Numbers of family members & $1.21(0.60$ to 2.43$)$ & $1.26(0.61$ to 2.61$)$ & $1.07(0.51$ to 2.24$)$ \\
\hline A history of hay fever and familial asthma & $1.54(0.71$ to 3.35$)$ & $1.94(0.85$ to 4.43$)$ & $2.42(0.99$ to 5.93$)$ \\
\hline \multicolumn{4}{|l|}{ Tobacco smoking } \\
\hline Never smoker & reference & reference & reference \\
\hline Ex-smoker at employment & $0.81(0.25$ to 2.64$)$ & $0.70(0.21$ to 2.35$)$ & $0.83(0.24$ to 2.84$)$ \\
\hline Smoking at start of employment & $1.31(0.64$ to 2.69$)$ & $1.29(0.61$ to 2.75$)$ & $1.46(0.66$ to 2.84$)$ \\
\hline Light smoker & $0.47(0.06$ to 3.98$)$ & $0.43(0.05$ to 3.72$)$ & $0.60(0.07$ to 5.14$)$ \\
\hline Moderate smoker & $1.62(0.78$ to 3.38$)$ & $1.49(0.68$ to 3.26$)$ & $1.82(0.82$ to 4.03$)$ \\
\hline Heavy smoker & $1.11(0.37$ to 3.40$)$ & $1.64(0.50$ to 5.43$)$ & $1.23(0.39$ to 4.01$)$ \\
\hline Smoking at termination of employment or diagnosis & $1.52(0.77$ to 3.00$)$ & $1.70(0.84$ to 3.42$)$ & $1.72(0.85$ to 3.51$)$ \\
\hline History of bronchitis & $4.00(0.25$ to 63.95$)$ & $3.68(0.20$ to 66.49$)$ & $5.87(0.31$ to 112.00$)$ \\
\hline History of childhood asthma & $2.00(0.18$ to 22.06$)$ & $3.02(0.26$ to 34.86$)$ & $11.61(0.63$ to 213.84$)$ \\
\hline History of dermatitis & $1.21(0.32$ to 4.52$)$ & $1.96(0.49$ to 7.84$)$ & $1.79(0.43$ to 7.55$)$ \\
\hline Maori/Samoan ethnicity & $1.48(0.50$ to 4.34$)$ & $1.42(0.46$ to 4.45$)$ & $1.18(0.38$ to 3.63$)$ \\
\hline Wheeze on auscultation at pre-employment examination & $4.00(0.56$ to 28.40$)$ & $4.81(0.65$ to 35.44$)$ & $6.55(0.56$ to 77.10$)$ \\
\hline Being overweight (BMI 25.0-29.9) & $1.13(0.56$ to 2.31$)$ & $1.10(0.52$ to 2.36$)$ & $1.41(0.60$ to 3.28$)$ \\
\hline Being obese $(B M I \geqslant 30.0)$ & $2.09(0.71$ to 6.16$)$ & $2.17(0.68$ to 6.87$)$ & $2.82(0.79$ to 10.04$)$ \\
\hline \multicolumn{4}{|l|}{ Spirometric variables } \\
\hline FVC (\% of predicted) & 1.01 (0.97 to 1.04$)$ & $1.01(0.98$ to 1.05$)$ & 1.00 (0.96 to 1.04$)$ \\
\hline $\mathrm{FEV}_{1}$ (\% of predicted) & 0.98 (0.95 to 1.01$)$ & $0.99(0.96$ to 1.02$)$ & 0.98 (0.95 to 1.01$)$ \\
\hline FER (FEV $1 /$ FVC \%) & 0.93 (0.88 to 0.98$)$ & 0.93 (0.88 to 0.99$)$ & 0.93 (0.88 to 0.99$)$ \\
\hline \multicolumn{4}{|l|}{ Stratified analysis } \\
\hline FER $\geqslant 80.0 \%$ & reference & reference & reference \\
\hline FER $75.0-79.9 \%$ & 2.22 (1.05 to 4.72$)$ & 2.05 (0.93 to 4.52$)$ & 3.07 (1.26 to 7.50$)$ \\
\hline FER $70.0-74.9 \%$ & 3.35 (1.15 to 9.75$)$ & 2.62 (0.85 to 8.07$)$ & $3.46(1.01$ to 11.89$)$ \\
\hline FER $<70.0 \%$ & $2.04(0.20$ to 20.56$)$ & 2.09 (0.20 to 21.68 ) & $2.94(0.24$ to 36.46$)$ \\
\hline
\end{tabular}


$\mathrm{p}=0.038$ ). A pre-employment FER of $70.0-74.9 \%$ increased the risk for OAAS further (crude OR 3.35, p=0.026). Individuals with the lowest level of FER $(<70.0 \%)$ also had an increased risk, but because of the small number $(n=4)$, the finding was not statistically significant (adjusted OR 2.94, $95 \%$ CI 0.24 to $36.46, \mathrm{p}=0.546$ ).

\section{DISCUSSION}

We found a positive association between hay fever diagnosed at, or after, employment and OAAS (adjusted OR 3.58, 95\% CI 1.57 to $8.21, p=0.003$ ). A family history of asthma, childhood asthma, tobacco smoking, a history of bronchitis, a history of dermatitis, obesity, and Maori/Samoan ethnicity showed moderate, but non-significant associations.

There was no association between the pre-employment FVC and $\mathrm{FEV}_{1}$ and OAAS. Workers that are medically selected for high exposure areas usually do not have evident respiratory disease. In spite of this, a statistically significant negative association was found between the FER at preemployment and OAAS (adjusted OR 0.93, p=0.017). Furthermore, the risk of developing OAAS in individuals with an FER of $75.0-79.9 \%$ was more than twice that of individuals with an FER of $\geqslant 80.0 \%$ (crude OR 2.22, 95\% CI 1.05 to 4.72). This risk increased further with a preemployment FER of $70.0-74.9 \%$ (crude OR 3.35, 95\% CI 1.15 to 9.75$)$. In the adjusted analysis, the associations and the increasing risk remained positive (adjusted OR 3.07 and 3.46 respectively). This indicates that even a mild reduction in FER at pre-employment predicts an increased risk of OAAS.

The main limitation was the small size of the cohort, 545 individuals yielding 45 cases. Increasing the numbers through recruitment of additional plants would have increased the power, albeit at the expense of other factors, for example, selection bias and differences in exposure. Because BHR was not used in selection at the smelter the healthy worker effect was not as large as it may be in some plants.

The strength of the study lies in the matched case-control design, accurate work histories, and good hygiene data. Inconsistencies because of peak exposures, examined using the two methods of adjustment (exposure index and exposure grade) produced largely similar results (table 2). We also believe that bias was minimised for risk factors studied at pre-employment, as subjects did not know if they were going to develop OAAS.

There are few other analytical studies examining the susceptibility for OAAS. When examining cross-sectional studies, Fritschi et al found a positive association between rhinitis and work related asthmatic symptoms (WRAS) in potroom workers (OR 3.5, 95\% CI 1.2 to 10.6). ${ }^{17}$ Kongerud et al found a statistically non-significant OR of 1.38 between WRAS and allergy, which was consistent with a subsequent longitudinal study. ${ }^{14}{ }^{15}$ The lower OR than that in our study may be because respiratory symptoms, rather than diagnosed cases of OAAS were examined. Søyseth and Kongerud also found statistically non-significant increased risks between various respiratory symptoms, including WRAS and atopy (OR 1.0-2.3). ${ }^{6}$

A Dutch case-control study, similar in design to ours, found no significant associations with a history of childhood asthma, familial asthma, or cigarette smoking. ${ }^{18}$ The FER was significantly lower in cases than controls at pre-employment, which is consistent with our study. There was a positive association and a dose-response relation between pre-employment eosinophil count and OAAS (OR 1.28, p=0.0002), suggesting that a raised eosinophil count at pre-employment, in the absence of respiratory symptoms or obvious pathology, may contribute to the subsequent development of OAAS. A prospective cohort study by Sorgdrager et al also found that atopy was associated with OAAS (OR 1.27, 95\% CI 1.02 to 1.58). ${ }^{16}$ Workers with atopy developed OAAS at lower fluoride exposure levels.

The association between hay fever and OAAS is potentially important. Hay fever has been consistently associated with community acquired asthma in adults. ${ }^{23-26}$ When other factors of atopy (eczema, eosinophilia, and raised IgE) are included, the risk increases further. ${ }^{27}{ }^{28}$ In our study only hay fever was assessed because skin testing, IgE, and eosinophil levels were not performed at pre-employment.

Hay fever is the clinical manifestation of a type 1 hypersensitivity reaction of the nasal and conjunctival mucosa to airborne allergens. In allergic rhinitis, obstruction of the nose may cause the filter function to fail, resulting in increased exposure of the lower airways to allergens and irritants. ${ }^{29}$ Furthermore, there is evidence that some persons with allergic rhinitis may also have underlying airway inflammation. Bronchoalveolar lavage, bronchial biopsy, and sputum studies provide evidence that some persons with allergic rhinitis exhibit inflammatory processes in the lower airways. ${ }^{30-32}$ An Italian study examined inflammatory features in bronchial airways of non-asthmatic allergic rhinitis patients and found a significantly higher number of eosinophils in the sputum of non-asthmatic subjects with allergic rhinitis compared to controls. ${ }^{33}$ Furthermore, the absolute number of sputum eosinophils was significantly correlated with increasing BHR $(r=0.73, \mathrm{p}=0.007)$. Therefore, subclinical inflammatory changes within the lower airways are present in subjects with allergic rhinitis, even in the absence of clinical asthma.

BHR is common in persons with allergic rhinitis. Approximately $30-40 \%$ of persons with allergic rhinitis may have BHR. ${ }^{29}{ }^{30}{ }^{34}$ BHR has been shown to be a risk factor for OAAS, and if workers with hay fever have BHR, they may be at risk of developing OAAS. Furthermore, if rhinitis reduces filtration of particulate and causes higher bronchial exposures to irritants, this would aggravate underlying bronchial inflammation and lead to clinical asthma. This is supported by studies of OAAS finding increased eosinophil levels at preemployment and diagnosis. ${ }^{18} 35$

$\mathrm{BHR}$ is subject to temporal variation; for example, allergic asthmatic patients have seasonal BHR that parallel allergen exposure..$^{36}$ Polosa confirmed substantial sputum eosinophilia in non-asthmatic allergic rhinitis patients during the pollen season, but near normal counts out of season. ${ }^{37}$ Antiinflammatory treatments such as antihistamines, nasal glucocorticoids, sodium cromoglycate, and immunotherapy are very effective in reducing nasal (and airway) inflammation. ${ }^{29}{ }^{37}$ These agents may be a valuable adjunct to the treatment for allergic and non-allergic asthma. ${ }^{29}$ The clinical implication is that aluminium workers with hay fever could be screened for BHR during the pollen season and/or when they experience symptoms of hay fever. Those with BHR could be temporarily removed from irritant exposures and/or given anti-inflammatory treatment to reduce inflammation and restore nasal filter function. BHR testing can be done serially during this period to assess when airway responsiveness returns to normal.

The association between hay fever and OAAS is unlikely to be a causal one, but it is plausible that hay fever increases the risk of susceptible individuals for developing OAAS. This susceptibility could be part of an ongoing airway inflammatory process in subjects with atopy, which may be independent of occupational factors; ${ }^{38}$ however it seems likely that irritants can aggravate or trigger this process, leading to asthma. We recommend that job applicants with atopy and an FER of $<80 \%$ at pre-employment be screened for BHR. Those individuals with BHR and those with an FER $<75 \%$ 
should either not be accepted for jobs with fluoride exposure or very carefully monitored with spirometry and serial BHR testing during their employment.

While underlying and pre-existing risks are important, workplace exposures remain the most important likely cause of OAAS. Therefore, it remains of the utmost importance for the prevention of ill health in workers to reduce these exposures to the absolute minimum.

\section{ACKNOWLEDGEMENTS}

We would like to thank the New Zealand Aluminium Smelters Ltd for their support for this study as part of their continued commitment to improve the health of their staff.

\section{Authors' affiliations}

C G Barnard, New Zealand Aluminium Smelters (NZAS) Ltd, Private Bag 90110 , Invercargill, New Zealand

D I McBride, H M Firth, G P Herbison, Department of Preventive and Social Medicine, University of Otago, PO Box 913, Dunedin, New Zealand

Support: This study was made possible through the support of NZAS Ltd Conflict of interest: Dr Barnard was medical advisor to NZAS from 1998 to 2003

\section{REFERENCES}

1 Frostad EW. Fluorine intoxication in Norwegian aluminium plant workers Tiddsk Nor Laegefor 1936;56:179.

2 Evang K. Investigation among Norwegian workmen as to the occurrence of bronchial asthma, acute cryolite exposure and 'fluorosis'. Nord Hyg Tidsskr 1938; 19:117-48.

3 Bruusgaard A. Asthma-like disease among Norwegian aluminium plant workers. Tidsskr Nor Laegefor 1960;80:796-7.

4 Simmonson BG, Sjöberg A, Rolf $C$, et al. Acute and long-term airway hyperreactivity in aluminium salt exposed workers with nocturnal asthma. Eur J Respir Dis 1985;66:105-18.

5 Hiortsberg U, Nise G, Ørbaek P, et al. Bronchial asthma due to exposure to potassium aluminiumtetrafluoride. Scand J Work Environ Health 1986; 12:223.

6 Søyseth V, Kongerud J. Prevalence of respiratory disorders among aluminium potroom workers in relation to exposure to fluoride. $\mathrm{Br} J$ Ind Med 1992;49:125-30.

7 Søyseth V, Kongerud J, Ekstrand J, et al. Relation between exposure to fluoride and bronchial responsiveness in aluminium potroom workers with work-related asthma-like symptoms. Thorax 1994;49:984-9.

8 Fritschi L, Sim MR, Forbes A, et al. Respiratory symptoms and lung-function changes with exposure to five substances in aluminium smelters. Int Arch Occup Environ Health 2003;76:103-10.

9 Lund K, Refnes M, Sandstrøm T, et al. Increased CD3 positive cells in bronchoalveolar lavage fluid after hydrogen fluoride inhalation. Scand J Work Environ Health 1999;25:326-34.

10 Kongerud J, Søyseth V. Methacholine responsiveness, respiratory symptoms and pulmonary function in aluminium potroom workers. Eur Respir $J$ and pulmonary func

11 Daroowalla F, Kaufman J, Nelson N, et al. Bronchial responsiveness and respiratory risk factors in new hires to an aluminium potroom. Am J Respir Crit Care Med 1996;153:A183.

12 Daroowalla F, Kaufman J, Nelson N, et al. Six month follow-up of symptoms and bronchial responsiveness in a longitudinal study of aluminium potroom workers. Am J Respir Crit Care Med 1997; 155:A136.
13 Daroowalla F, Kaufman J, Nelson N, et al. New bronchial responsiveness and asthma symptoms in a cohort of aluminium potroom workers. Am J Respir Crit Care Med 1998;157:A882.

14 Kongerud J, Grønnesby JK, Magnus P. Respiratory symptoms and lung function of aluminium potroom workers. Scand J Work Environ Health 1990;16:270-7.

15 Kongerud J, Samuelsen SO. A longitudinal study of respiratory symptoms in aluminium potroom workers. Am Rev Respir Dis 1991;144:10-16.

16 Sorgdrager B, De Looff AJA, De Monchy JGR, et al. Occurrence of occupational asthma in aluminium potroom workers in relation to preventive measures. Int Arch Occup Environ Health 1998;71:53-9.

17 Fritschi L, Beach J, Sim M, et al. Respiratory symptoms and lung function in two pre-bake aluminium smelters. Am J Ind Med 1999;35:491-8.

18 Sorgdrager B, Pal TM, De Looff AJA, et al. Occupational asthma in aluminium potroom workers related to pre-employment eosinophil count. Eur Respir J 1995;8:1520-4.

19 Mackay IR, Oliphant RC, Laby B, et al. An immunologic and genetic study of asthma in workers in an aluminium smelter. J Occup Med 1990;32:1022-6.

20 American Thoracic Society. Lung function testing: selection of reference values and interpretative strategies. Am Rev Respir Dis 1991;144:1202-18.

21 De Hamel FA, Welford B. Lung function in Maoris and Samoans working in New Zealand. N Z Med J 1983;96:560-2.

22 D'Souza W, Lewis S, Cheng $S$, et al. The prevalence of asthma symptoms, bronchial hyperresponsiveness and atopy in New Zealand adults. N Z Med J 1999; 1 12:198-202

23 Strachan DP, Butland BK, Anderson HR. Incidence and prognosis of asthma and wheezing illness from early childhood to age 33 in a British cohort. BMJ 1996:312:1195-9.

24 McWhorter WP, Polis MA, Kaslow RA. Occurrence, predictors, and consequences of adult asthma in NHANESI and follow-up survey. Am Rev Respir Dis 1989;139:721-4.

25 Abramson M, Kutin JJ, Raven J, et al. Risk factors for asthma among young adults in Melbourne, Australia. Respirology 1996;1:291-7.

26 Plaschke PP, Janson C, Norrman E, et al. Onset and remission of allergic rhinitis and asthma and the relationship with atopic sensitisation and smoking Am J Respir Crit Care Med 2000;162:920-4.

27 Bodner C, Godden D, Ross S, et al. Bronchial hyperresponsiveness and adult onset wheeze: the influence of atopy. Eur Respir J 1999:14:335-8.

28 Bodner CH, Ross S, Little J, et al. Risk factors for adult onset wheeze. Am J Respir Crit Care Med 1998; 157:35-42.

29 Fireman P. Rhinitis and asthma connection: management of coexisting upper airway allergic diseases and asthma. Allergy Asthma Proc 2000;21:45-53.

30 Bradley BL, Azzawi M, Jacobson M, et al. Eosinophils, T-lymphocytes, mast cells, neutrophils and macrophages in bronchial biopsy specimens from atopic subjects with asthma: comparisons with biopsy specimens form atopic subjects without asthma and normal control subjects and relationship to bronchial hyperresponsiveness. J Allergy Clin Immunol 1991;88:661-74.

31 Diukanovic R, Lai CKW, Wilson JW, et al. Bronchial mucosal manifestation of atopy: a comparison of markers of inflammation between atopic asthmatics, atopic non-asthmatics and healthy controls. Eur Respir J 1992:5:538-44.

32 Foresi A, Leone C, Pelucchi A, et al. Eosinophils, mast cells and basophils in induced sputum from patients with seasonal allergic rhinitis and perennial asthma: relationship to methacholine responsiveness. J Allergy Clin Immunol 1997; 100:58-64

33 Polosa R, Ciamarra I, Mangano G, et al. Bronchial hyperresponsiveness and airway inflammation markers in nonasthmatics with allergic rhinitis. Eur Respir J 2000;15:30-5.

34 Badier M, Guillot C, Delpierre S, et al. Value of bronchial challenge in scuba diving candidates. J Asthma 2000;37:661-5.

35 Middtun $\mathrm{O}$. Bronchial asthma in the aluminium industry. Acta Allergol (Kovenhavn) 1960;15:208-22.

36 Tilles SA, Bardana Jr EJ. Seasonal variation in bronchial hyperreactivity (BHR) in allergic patients. Clin Rev Allergy Immunol 1997;15:169-85.

37 Polosa R. Correspondence: Bronchial hyperresponsiveness and airway inflammatory markers in non-asthmatics with allergic rhinitis. Eur Respir J 2000;16:793.

38 Braman SS, Barrows AA, DeCotiis BA, et al. Airway hyperresponsiveness in allergic rhinitis. A risk factor for asthma. Chest 1987;91:671-4. 